Mojca Jarc

UDK 37.011.3-052(=163.6):378(44)

Univerza v Ljubljani

DOI: $10.4312 /$ vestnik.7.169-189

Fakulteta za družbene vede

Mojca.jarc@fdv.uni-lj.si

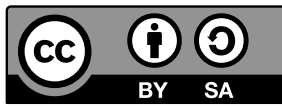

\title{
"ZDAJ MORATE POZABIT VSE, KAR STE SE PREJ NAUČILI«: GRADNJA MEDKULTURNIH KOMPETENC PRI SLOVENSKIH ŠTUDENTIH NEFILOLOŠKE FAKULTETE V FRANKOFONEM AKADEMSKEM OKOLJU
}

\section{UVOD}

Internacionalizacija je v 90ih letih prejšnjega stoletja postala ključna tema visokega šolstva (Teichler 2004). Številni evropski študenti so deležni mednarodnega priznavanja diplom in lahko podiplomski študij nadaljujejo v tujini ali pa se že med študijem udeležijo izmenjave ter del svojih študijskih obveznosti opravijo na gostujoči univerzi. Ob velikemu uspehu gibanja mednarodnih študijskih izmenjav, ki se je v Evropi razmahnilo predvsem po zaslugi programa Erasmus, ni pomemben samo obseg teh izmenjav, ampak tudi dejstvo, da so se izmenjave izkazale kot sredstvo za pridobivanje medkulturnih kompetenc (Doyle in dr. 2010). Vse večja mobilnost študentov odpira nova vprašanja, med drugim tudi vprašanje podobnosti in razlik med nacionalnimi izobraževalnimi sistemi (Teichler 2009). Z vidika spodbujanja izmenjav namreč zlasti pri študentih nefiloloških fakultet poznavanje tujega jezika in kulture akademskega okolja na gostujoči ustanovi ostaja pomembna ovira pri študiju v tujini (Jašková in Heczková 2010, Doyle in dr. 2010).

Ena od možnih rešitev te težave se nakazuje $\mathrm{z}$ uporabo angleščine kot lingue france (LF) akademskega okolja, a ta možnost prinaša številne težave, na kar so opozarjali avtorji v različnih anglofonih in neanglofonih okoljih (Swales 1997, Coleman 2006, Kalin Golob in dr. 2014). Drugi odgovor na jezikovno-kulturne ovire pri izmenjavah je spodbujanje večjezičnosti. Dodano vrednost večjezičnosti prepoznavajo tudi sami študenti. Ker študenti na izmenjavi pogosto vseh aktivnosti na gostujoči instituciji ne morejo ali ne želijo opraviti v angleškem jeziku, je za njihovo uspešno mednarodno izkušnjo pomembno, da obvladajo jezik okolja, v katerem študirajo. Študija Doylove in sodelavcev (2010) je izpostavila neznanje jezika gostujoče države kot največjo oviro pri mobilnosti študentov. V nekaterih primerih pa je večjezičnost celo pogoj za mednarodno izmenjavo. Kljub jasnim znakom prevlade angleščine kot LF v akademskem svetu (Coleman 2006) je torej za študenta v današnjem svetu znanje več tujih jezikov nujnost.

Številne študije so raziskovale vlogo angleščine kot LF in način vzpostavljanja identitete tujega študenta v anglofonem okolju ali v globaliziranem mednarodnem okolju, kjer 
je angleščina pogosto jezik poučevanja (Ventola in Mauranen 1996, Canagarajah 2007, Flowerdew in Wang 2015). Dosti manj pa je raziskav, ki bi se ukvarjale z vzpostavljanjem identitete v študentovem drugem tujem jeziku (Henry 2011).

Medkulturne vsebine naj bi sicer bile prisotne v programih francoskega splošnega jezika, zdi pa se, da je ta komponenta v nekoliko manjši meri poudarjena pri poučevanju tujega jezika stroke, čeprav tudi tu didaktiki opozarjajo na potrebo po vključevanju tovrstnih poudarkov v jezikovne programe (Challe 2002, Mangiante in Parpette 2004, Carras in dr. 2007). Za snovalca programa francoščine kot tujega strokovnega jezika je razumevanje percepcije tujega ( $v$ našem primeru slovenskega) študenta zelo pomembno, a težje opredeljivo. Carras in dr. (2007) namreč poudarjajo, da je največja težava pri pridobivanju tovrstnih podatkov v tem, da niso eksplicitno izraženi v besedilih, ki jih učitelj izbere za poučevanje. O medkulturnih vidikih torej ni mogoče sklepati z analizo diskurzivnega korpusa določenega področja, ampak zanesljive podatke lahko dobimo samo z intervjuji uporabnikov, ki se znajdejo v položajih, ko ugotovijo, da domača in tuja kultura na različen način obravnavata določen pojav in da se bodo zato morali prilagoditi delovanju v novi kulturi.

Podatki o tem, kako tuji študenti v frankofonem okolju rešujejo vprašanja medkulturne narave, so relativno skopi in nepopolni. Raziskave se večinoma ukvarjajo $\mathrm{z}$ analizo pozitivnih in negativnih učinkov določenih dejavnikov na medkulturno komunikacijo. Paquin in Hock (2014) sta analizirala pozitivne in negativne učinke medkulturnih srečanj, nekatere študije (Pitts 2009; Brisset in dr. 2010) so se ukvarjale s psihološkimi dejavniki, ki vplivajo na družbenokulturno prilagajanje; $z$ vidika poučevanja tujega jezika so preučevali vplive učenja tehnik argumentacije na uspeh tujih študentov v frankofonem okolju (Diamanti 2011). Poleg študij učinkov posameznih dejavnikov na medkulturna srečanja v univerzitetnem frankofonem okolju je v zadnjem času izšlo nekaj praktičnih pedagoških priročnikov, namenjenih učiteljem francoščine kot tujega jezika stroke na nefiloloških fakultetah (Carras in dr. 2007, Cislaru in dr. 2009, Mangiante in Parpette 2011), dosti manj pa je znanega o tem, kako govorci francoščine kot tujega jezika stroke dojemajo zahteve akademske kulture, v katero se vključujejo, in s kakšnimi težavami se pri tem srečujejo.

Skozi perspektivo nezadostnih jezikovnih kompetenc v drugem tujem jeziku se pri tem postavljajo vprašanja študentovih predstav o tuji akademski kulturi in o načinu bivanja znotraj te kulture. Namen pričujoče raziskave je ugotoviti, s kakšnimi omejitvami, povezanimi z gradnjo medkulturnih kompetenc, se srečujejo slovenski študenti nefilološke fakultete ob opravljanju študijskih obveznosti v okviru svojega dodiplomskega ali podiplomskega študija na frankofoni instituciji. Naš cilj je prispevati k razumevanju načinov gradnje medkulturnih kompetenc pri študentih nefilološke fakultete in procesov, ki potekajo pri zaznavanju značilnosti francoske oz. frankofone akademske kulture. Pri tem smo sledili integrativnemu komunikacijskemu pristopu, ki na medkulturno prilagajanje gleda kot na »pojav, pri katerem si posamezniki po selitvi v nepoznano kulturno okolje prizadevajo vzpostaviti in ohraniti relativno stabilen, recipročen in funkcionalen odnos z okoljem« (Kim 2012: 233). 


\section{KONTEKST ŠTUDIJE IN UDELEŽENCI}

Na Fakulteti za družbene vede Univerze v Ljubljani (FDV), kjer je bila raziskava izvedena, je internacionalizacija $\mathrm{v}$ zadnjih letih med prioritetami tako na raziskovalnem kot na pedagoškem področju. Pomemben vidik internacionalizacije je tudi omogočanje izmenjav za študente in spremljanje študentov, ki so svojo študijsko in poklicno pot nadaljevali v tujini. Študenti se lahko izmenjave udeležijo, če so uspešno opravili prvi letnik dodiplomskega študija. Po opravljenem dodiplomskem študiju se lahko študenti vpišejo na podiplomski študij, ali pa študij nadaljujejo na kaki drugi slovenski fakulteti oz. v tujini.

Pričujoča študija je del širšega projekta, ki ga izvajamo v okviru analize potreb slovenskih študentov družbenih ved, ki se učijo francoskega jezika. Glavnino frankofone populacije tvorijo študenti smeri Mednarodni odnosi (MO) in Evropske študije (EŠ). Ti študenti imajo na dodiplomski ravni v predmetniku med obveznimi predmeti dva tuja jezika. Tisti, ki imajo predznanje francoščine, se lahko vključijo v predmet francoščine kot tujega strokovnega jezika. Študenti z znanjem dveh tujih jezikov, ki nadaljujejo študij na podiplomski ravni, lahko brez predznanja izberejo predmet Francoščina kot tretji tuji jezik. Večina študentov ima zunaj predavanj francoskega jezika malo stikov s francosko kulturo. Njihove predhodne izkušnje s francoskim jezikom in kulturo so pogosto omejene na učenje splošnega jezika in spoznavanje frankofone kulture bodisi v okviru rednega kurikula ali obšolskih dejavnosti v srednješolskem izobraževalnem sistemu; nekateri so potovali v francosko govoreče države, nekaj pa se jih je že v srednji šoli udeležilo mednarodne izmenjave.

Vsi intervjuvanci so imeli ob vstopu v frankofono akademsko okolje predznanje francoskega jezika. Za večino je francoščina drugi tuji jezik, za nekatere pa tretji ali celo četrti tuji jezik. Skoraj brez izjeme pa je angleščina v njihovem naboru prvi tuji jezik. Učni načrt za francoščino $\mathrm{v}$ gimnazijskih programih $\mathrm{v}$ okviru predpisanih vsebin pripisuje pomembno mesto razvijanju medkulturne ozaveščenosti, saj je ta zmožnost opredeljena med ključnimi cilji predmeta (Lah in ostali 2008), prav tako pa so medkulturne vsebine sestavni del učbenikov francoskega jezika (Lah 2012). Tovrstne vsebine so predpisane tudi v programih ostalih tujih jezikov. Predvidevamo torej lahko, da imajo do svoje akademske izkušnje v frankofonem okolju študenti že določeno raven usvojenega znanja o pomenu medkulturnih vidikov pri učenju tujega jezika nasploh in posebej pri spoznavanju francoske kulture.

$\mathrm{S}$ študenti in diplomanti smeri MO in EŠ smo izvedli serijo polstrukturiranih intervjujev. S podatki, ki so nam jih udeleženci posredovali v intervjujih, smo skušali dobiti vpogled v življenje tujega študenta na frankofoni univerzitetni izobraževalni ustanovi, bodisi na dodiplomski ali na podiplomski ravni. Zaradi usmerjenosti v analizo potreb nas je posebej zanimalo, kako medkulturna izkušnja na izmenjavi v frankofonem okolju vpliva na razvoj študentovih potreb pri učenju francoščine kot tujega jezika stroke. Predpostavljamo, da k uspehu integracije $\mathrm{v}$ frankofono okolje prispevajo tako jezikovne kot medkulturne kompetence. Pri analizi medkulturnih kompetenc so nas vodila naslednja vprašanja: 
1. Kako študenti na temelju izkušnje študija v frankofonem okolju konceptualizirajo svojo identiteto?

2. V čem vidijo posebnost (,drugačnost') frankofone kulture?

3. Na kakšen način izgrajujejo svoje medkulturne kompetence $v$ frankofonem okolju?

4. Katere vrste strategij in zmožnosti bi bilo koristno razvijati pri teh študentih pred odhodom na izmenjavo?

\section{METODA}

Študija se naslanja na kvalitativno metodologijo, ki je primeren okvir za našo raziskavo, ker med drugim omogoča, da v ospredje stopijo udeleženci (Walford 2001). Osredinjenost na učenca je hkrati tudi eno od izhodišč za učitelja tujega strokovnega jezika, ki snuje program na temelju analize potreb udeležencev (Mangiante in Parpette 2004). Pri zbiranju podatkov smo uporabili polstrukturirani intervju. To je v didaktiki in družboslovju široko uporabljena tehnika, s katero lahko določeno vedênje opazovane osebe postavimo v kontekst; na ta način lahko ugotavljamo, kakšne pomene določenim pojavom pripisujejo udeleženci in kako so sami doživljali določeno izkušnjo (Seidman 2006).

Zbiranje podatkov je potekalo med januarjem in junijem 2014 ter v septembru 2015. Celoten korpus obsega 29 intervjujev. V intervjuju so sodelovali študenti, diplomanti in učitelji na smereh MO in EŠ na FDV. Iz korpusa smo za potrebe analize medkulturnih kompetenc uporabili 12 intervjujev s študenti, ki imajo mednarodno akademsko izkušnjo. Štirje študenti so v frankofonem okolju opravljali podiplomski študij, ostali so bili na frankofonih fakultetah v okviru eno- ali dvosemestrske izmenjave Erasmus. Šest intervjuvancev je bilo ženskega spola, šest pa moškega spola. V času izvajanja intervjuja so bili stari od 20 do 29 let.

S tekstovno analizo intervjujev smo ugotavljali, kakšne so izkušnje študentov z žanri. Ker pa je žanr v naši raziskavi razumljen kot družbena praksa (Christie in Martin 2000), smo v intervjuju dobili tudi številne podatke o kontekstu, $v$ katerem poteka sporočanje študentov v frankofonem okolju. Študente smo našli na podlagi seznamov študentov, ki so v okviru svojega dodiplomskega študija izbrali francoščino kot jezik stroke oziroma so imeli predmet Francoščina kot tretji tuji jezik stroke v okviru svojega podiplomskega študija. S študenti smo vzpostavili stik bodisi v okviru predavanj francoščine ali preko seznamov nekdanjih študentov. Velika večina se jih je povabilu na intervju odzvala. Intervjuje smo izvajali v prostorih FDV ali preko Skypa, jih posneli in transkribirali. Nato smo jih analizirali in kodirali. Študentom smo zagotovili anonimnost, zato so v nadaljevanju njihove izjave opremljene s kodirnimi šiframi. Prizadevali smo si, da smo pri podajanju izsledkov podrobno opisali tudi kontekstualne okoliščine ${ }^{1}$.

1 Ta metoda se je po Geertzevem zgledu uveljavila pod imenom thick description. 


\section{IZSLEDKI IN ANALIZA}

Medkulturna kompetenca je pomemben element sporazumevalne zmožnosti, saj kaže na to, kako govorec tujega jezika dojema lokalni kulturni okvir in kako se nanj prilagaja. V perspektivi učenja jezika stroke Carrasova in dr. (2007: 45) medkulturno ozaveščenost opredelijo kot »sposobnost opazovanja in analize vseh vidikov vedênja tujega sogovornika« in sposobnost "prilagajanja lastnega vedênja« na temelju teh podatkov. Mangiante (2012) z diskurzivno analizo korpusa pisnih in ustnih besedil sicer med drugim pokaže, da eksplicitne reference na lokalni kulturni okvir deloma najdemo tudi v besedilih, ki so tipična za univerzitetno okolje. Vendar pa tovrstna analiza ne daje podatkov o študentovem dojemanju medkulturnih elementov.

Vpogled $\mathrm{v}$ ta vidik gradnje medkulturne ozaveščenosti smo dobili $\mathrm{z}$ analizo intervjujev. Pri obravnavi rezultatov smo po zgledu Kimove (2009) izhajali iz konceptov identitete in medkulturne kompetence. Raziskave so pokazale, da identitetna inkluzivnost in varnost pomagata pri vzpostavljanju medkulturne kompetence. Identitetna inkluzivnost označuje posameznikovo pripravljenost, da stopa $\mathrm{v}$ odnose s pripadniki drugih kultur, identitetha varnost pa posameznikov občutek varnosti v okviru lastne identitete. Prilagajanje na novo kulturo je proces, ki vključuje gradnjo nove - medkulturne identitete. V tem procesu se preko stresa in prilagajanja zabrišejo meje med domačo in tujo kulturo. Rezultat gradnje medkulturne identitete je usmerjenost posameznika, ki integrira kategorije obeh kultur, namesto da bi jih ločevala (Kim 2015). Da bi ugotovili, kako se pri naših intervjuvancih odražata identitetna inkluzivnost in varnost ter kako poteka prilagajanje na univerzitetno okolje, smo analizirali štiri vidike njihove medkulturne izkušnje: opredelitev lastne identitete, razumevanje frankofone akademske kulture, omejitve medkulturne ozaveščenosti in strategije razreševanja težav medkulturne narave.

\subsection{Opredelitev lastne identitete}

V integrativnem modelu identiteta ni statična, ampak je podvržena dinamičnim procesom, pod vplivom katerih se spreminja. Zanimalo nas je, kako študentje konceptualizirajo lastno identiteto $v$ frankofonem okolju. $V$ izpovedih naših intervjuvancev je mogoče sklepati na mešanico elementov identitetne varnosti in inkluzivnosti, ki jih zaznamuje že na začetku njihovega procesa prilagajanja novi kulturi. Identitetna varnost naših intervjuvancev se kaže predvsem v pozitivni samopodobi, ki jo izražajo, ko opisujejo svoje načrte za študijsko bivanje in izkušnje bodisi v frankofonem, še dosti bolj pa v nefrankofonem tujejezičnem okolju, kjer predavanja potekajo $\mathrm{v}$ angleščini. Intervjuvanka, ki je bila na izmenjavi v Turčiji, pove, da je bila to zanjo izključno kulturna izkušnja, na kar so jih opozorili tudi ob prihodu na gostujočo institucijo. Zatrdi, da v študijskem smislu ni doživela nikakršnih presežkov in svojo samozavest utemeljuje prav samooceno doseženih jezikovnih zmožnosti: 
Kljub temu, da so to študenti, ki študirajo mednarodne odnose, je bilo njihovo znanje angleščine porazno. In seveda, da so imeli težave z izpitom iz teorij mednarodnih odnosov, ker niso niti vprašanja razumeli. Medtem, ko pa si ti vsa vprašanja razumel, si nekaj odgovoril, nekaj probal, malo višje v angleščini, da še profesor po možnosti ni razumel; je mislil, da si nekaj zelo fantastičnega napisal. Dejansko smo se te zadeve šli. Mi in pa Nemci, ki so itak briljirali v tej angleščini in znali obračat besede, tako da je bilo kar smešno. (Genex42)

Nasprotno pa so naši intervjuvanci na izmenjavo ali na podiplomski študij v frankofono okolje odšli z bolj določnimi cilji. Poleg splošno izraženih želja po novih doživetjih in srečanjih z novimi ljudmi sta izstopala dva motiva. Nekateri so svoje cilje opredelili s prednostnimi ambicijami razvoja jezikovnih zmožnosti, večina pa je pri opredeljevanju lastne identitete poudarjala svojo usmerjenost $\mathrm{v}$ druge kulture. Nekdanja podiplomska študentka Evropskih študij na Collège d'Europe si je to institucijo izbrala ravno zaradi dvojezičnosti študijskega programa.

Poleg omenjenih motivov prevladuje tudi motiv širšega vpogleda v študijsko smer. Tako se intervjuvanci veselijo možnosti, da bodo v predmetnik vključili predmete, ki jih na domači fakulteti ne bi mogli poslušati, in da bodo v stikih z gostujočimi predavatelji obravnavali nove tematike. Gradnja medkulturnih odnosov je za njih sredstvo za izpolnitev močnih želja, ki jih nekateri gojijo že od otroštva dalje, hkrati pa so zavestno usmerjeni v iskanje priložnosti za spoznavanje kultur, ki jih prepoznavajo kot bistveno drugačne od svojih. Kot pravi ena od študentk na Erasmus izmenjavi, je to šele prva od tovrstnih izkušenj na njeni poti:

Hotela sem izboljšat francoščino in spoznat en nov sistem, nekaj manj podobnega temu, kar imamo v Sloveniji ali na Hrvaškem. Od malega sem hotela v svet in izkušnja v Franciji je bila zame prva. (Genex33)

Njihova odločitev torej ni naključna, ampak je dobro premišljena. Verjamejo, da so se prav zaradi samozavesti in jasno izraženih ciljev izkazali že v izbirnem postopku, tako pri izbirnem intervjuju kot pri pisanju motivacijskega pisma. Odločna usmerjenost v cilj jih močno oddaljuje od pogosto uveljavljenega stereotipa študenta Erasmus v vlogi mednarodnega akademskega turista (Papatsiba 2006).

Po drugi strani pa bi od študentov MO in EŠ pričakovali, da so si določene medkulturne kompetence do izmenjave že pridobili in se v tem smislu ob odhodu v tujino ne dojemajo kot popolnoma neizkušene, kar pa se v intervjujih ni potrdilo. Večina jih je ob odhodu precej negotova. Dva intervjuvanca sta svoje občutke opisala z metaforo dojenčka, ki se mora naučiti plavati, ko je vržen v vodo. Iz izjave študenta četrtega letnika dodiplomskega študija je videti, da se kljub identitetni varnosti, ki izhaja iz trdne želje, da bi dosegel zastavljeni cilj, zaveda svoje neizkušenosti ob medkulturni izkušnji: 
Sem vedel, da je to ena taka neponovljiva izkušnja, kjer si kot dojenček vržen v vodo in moraš potem plavat. (Genex46)

Drugi ob tem spričo dejstva, da je francoščina njegov tretji tuji jezik, poudari, da je bil celo sam nad seboj presenečen, ker ni niti pomislil, da bo študij v frankofonem okolju tako naporen, ampak se je kljub opozorilom kolegov, da »rine z glavo skozi zid«, v novem okolju enostavno soočil z dejstvom, da mora obveznosti opraviti. Pri veliki večini intervjuvancev je čutiti, da je zlasti zaradi zavedanja o nepopolnem jezikovnem znanju v frankofonem okolju njihova samopodoba precej nižja od tiste, ki jo imajo njihovi slovenski kolegi v anglofonih okoljih. Zato nekateri že pred odhodom skušajo izboljšati svoje jezikovne zmožnosti.

Hodila sem samo v trimesečni pripravljalni tečaj pred Erasmusom, ker sem vedela, da imajo večinoma vse v francoščini tam in zahtevajo nek nivo in si nisem upala it. (...) Čeprav sem potem ugotovila, da nimam tako švoh znanja, ampak vseeno pomaga, če imašs francoskim lektorjem učne ure, da te malo pripravi na šok (...). (Genex45)

Pri tem nimajo samo težave s samooceno svojih jezikovnih zmožnosti, ampak se jim zlasti postavljajo dvomi o njihovi sposobnosti komunikacije na strokovnem področju in v univerzitetnem okolju. Le ena od intervjuvank je svojo izjemno bogato večjezičnost navedla kot prednost pri spopadanju z medkulturnimi težavami.

Ob prihodu na gostujočo univerzo se njihov proces akulturacije začne s sprejemanjem vloge izmenjavnega ali tujega študenta na frankofoni fakulteti. Glede na izhodiščno medkulturno usmerjenost večinoma ohranijo identitetno inkluzivnost in se čutijo sprejete v novem okolju, kar utrjuje tudi njihovo identitetno varnost. V družbi študentov, ki prihajajo iz celega sveta, se dobro počutijo. V nasprotju z raziskavami, ki kažejo, da se študenti v tujini predvsem družijo s kolegi iz svoje države (Papatsiba 2006), naši intervjuvanci tovrstnih srečanj niso iskali. Na fakulteti se počutijo sprejete: ena od intervjuvank vzdušje v tednu ob uvodnem sprejemu, ko potekajo dejavnosti, namenjene seznanjanju študentov Erasmus z novo institucijo, opiše kot »toplo«:

Oni za orientacijski teden so ogromno govorili in teh ključnih informacij je bilo zelo malo. Je bilo tako toplo in smo bili v teh učilnicah in itak prvi teden uloviš lahko vsako drugo besedo. (Genex34)

Vendar pa v stiku z novo akademsko kulturo kljub temu doživijo kulturni šok, kar je naraven pojav v procesu akulturacije (Kim 2015). Začetno destabilizacijo rešujejo tako, da postanejo del tako imenovane skupnosti Erasmus. Skupnost je stičišče za izmenjavo informacij in z omogočanjem komunikacije na ,nevtralnem območju‘ blaži učinek urgentnega 
prilagajanja na novo okolje, ki pred gostujoče študente postavlja številne konkretne zahteve za organizacijo bivanja. Hkrati pa se v sami skupini tudi poraja diferenciacija med študenti, ki niti nimajo namena načrtno vstopati v novo kulturo, če to ni nujno potrebno, in tistimi, ki si zastavijo cilj čim tesnejšega medkulturnega povezovanja. V prvi skupini so študenti, ki ne govorijo francoskega jezika; vse obveznosti na fakulteti opravljajo v angleščini in svoje stike omejujejo na skupnost Erasmus, kar eden od naših intervjuvancev opiše kot »Erasmus balonček«. V drugi skupini se združujejo študenti, ki imajo različne ravni predznanja francoskega jezika in se s tem znanjem želijo čim bolj vključiti v frankofono okolje, izboljšati svoje jezikovne zmožnosti, se poglobiti v študij in opravljati izpite tako v angleškem kot v francoskem jeziku. Ti prvo skupino označujejo kot ,turistično“ in nanjo gledajo kot na zaviralni dejavnik v lastnih prizadevanjih. Večina naših intervjuvancev se kljub temu, da iščejo varnost v celotni skupnosti Erasmus, želi priključiti drugi skupini, a vseskozi poudarjajo, da je njihov položaj izjemen, kar kaže na to, da je druga skupina pravzaprav v manjšini glede na celotno skupino. Med skupinama sicer poteka interakcija, vendar druga skupina predvsem išče povezave z rojenimi govorci francoskega jezika. Nekateri se pri vzpostavljanju tovrstnih stikov ne omejujejo samo na akademsko skupnost, kar eden od intervjuvancev ponovno opiše kot netipično usmerjenost.

Po drugi strani pa so med našimi intervjuvanci tudi študenti, ki zavestno iščejo stike samo $\mathrm{z}$ akademsko skupnostjo in se izogibajo kolegom na izmenjavi. Eden od intervjuvancev se označi za »bolj asocialnega tipa« in tako utemelji svojo usmerjenost v akademsko skupnost. Študenti, ki so se v frankofonem okolju udeležili podiplomskega študija, tovrstne delitve ne omenjajo, kar pripisujejo intenzivnosti študija.

Pri vključevanju v različne skupine torej za naše intervjuvance razvoj medkulturne identitete poteka večinoma, a ne izključno, v frankofonem univerzitetnem okolju. V akademski skupnosti začnejo primerjati nove pogoje s pogoji na svoji domači fakulteti in skušajo izkoristiti prednosti novega položaja. Pri tem si prizadevajo tudi za recipročnost odnosov. Pogajajo se o svoji identiteti, česar so sicer vajeni že v domačem okolju, a pridobljenih spretnosti ne morejo neposredno uveljaviti, saj težje predvidijo, v kakšnih normativnih okvirih delujejo. Ena od študentk pove, kako je delovanje pravil preizkusila v novem okolju:

Pri nas (na FDV), kadar so neka pravila, recimo nisi oddal tega, ali pa nisi prišel na neke vaje, pač te ni in te ni in to pač tako je. Medtem ko pa tu v Franciji, sicer ne vem, kako je za redne študente, ampak z nami, v mednarodni pisarni so bili zmeraj pripravljeni vsaj poslušat, če si imel kakšen problem, ali pa nisi mogel oddati neke stvari do roka (...). Jaz recimo sem se zelo bala, da mi ne bo časovno uspelo napisat seminarske naloge, ker je bila po praznikih oddaja, ampak sem jo oddala in sem dala korektno in sem dobila dobro oceno. (Genex34)

Študenti svojo identiteto gradijo tudi s sodelovanjem v izvenštudijskih dejavnostih. Nad ponujeno izbiro so izkazali navdušenje, saj $\mathrm{v}$ teh dejavnostih ponovno najdejo 
priložnost za utrjevanje varnosti in povezovanje. Eden od študentov pove, da se je pridružil glasbenemu društvu in je s kolegi organiziral dva koncerta, ki se ju je udeležila večina študentov na fakulteti. Poleg tega zelo močan vzgib za medkulturne stike in razširjene možnosti za gradnjo medkulturnih kompetenc študentom ponuja okolje zunaj univerzitetnih meja. Naš intervjuvanec svoj prehod od kulturnega šoka k medkulturnemu druženju z emigranti v stanovanjski soseski opisuje kot pozitivno izkušnjo.

Drugače pa itak, da ti je šok vse. Jaz sem na primer živel v Quartier Saint Michel, ki je slaven po tem, da tam živijo študenti in emigranti. In je en kulturni šok-polno nekih Arabcev, marché aux puces, ampak to ti potem rata taka dobra izkušnja, da hodiš tja samo barantat in barantaš z Arabci v francoščini...(Genex46)

Tovrstna akulturacija ne uspe vsem, saj zanjo bodisi ne najdejo priložnosti, ali pa si tovrstnih izkušenj niti ne želijo.

Čeprav se pri naših študentih opisi skupnosti Erasmus zelo približujejo prejšnjim opisom (npr. Papatsiba 2006) in bi zato lahko izhajali tudi iz stereotipno razširjenih predstav o mednarodnih študentih, pa se intervjuvanci prikažejo kot netipični izmenjavni študenti, saj imajo v nasprotju z večino jasno določene cilje, zaradi katerih so svojo identitetno varnost pripravljeni omejiti in v novem okolju tudi na račun stresnih situacij iskati priložnosti za razvoj medkulturne identitete.

\subsection{Razumevanje akademske kulture}

Način, kako intervjuvanci razumejo frankofono akademsko kulturo, se odraža v njihovem dojemanju različnih vidikov življenja v akademski skupnosti. Ob prihodu na gostujočo fakulteto morajo najprej urediti svoj status in ponovno najti študentsko rutino, ki so je bili vajeni na domači instituciji. Francosko okolje dojemajo kot kaotično:

Na začetku je bilo itak tako dezorganizirano, tako bolj divje, ampak potem postaneš del sistema in ni več nobenega problema (...) in se potem kar prilagodiš. (Genex46)

Zdi se jim, da so dezorientirani in da ne morejo zadostiti zahtevam. Ena od študentk na primer pove, da so imeli težave s prometom, ker včasih tramvaj ni deloval, večkrat so bili priča stavkam v javnem prevozu. Pri urejanju statusa so od nje zahtevali dokumente, ki jih ni mogla pridobiti, ker v Sloveniji ne obstajajo. Presenečena ugotovi, da se bo morala naučiti rokovati s čeki, ki jih do tedaj še ni videla. Ne razumejo, zakaj so za administrativno urejanje formalnosti porabili veliko časa, na koncu pa so nepričakovano vse uredili v dogovoru z odgovornimi osebami. 
Pri seznanjanju z načinom delovanja fakultete imajo težave, ker ne morejo slediti uvodni predstavitvi in ločiti pomembne od nepomembnih informacij. $V$ domačem okolju so vajeni, da so jim pomembni podatki dostopni v vizualni obliki in v elektronskih medijih, na frankofoni instituciji pa ta način podajanja ni tako uveljavljen, kar si ena od študentk interpretira kot nesposobnost rabe interneta:

In recimo, oni pridejo in je tam skupina, ki je zadolžena za to, in oni te informacije samo govorijo. Mi imamo zmeraj internetno stran in piše vse, kje je, in jaz sem se potem spraševala, zakaj niso recimo naredili PPT predstavitev z linki. Tudi če bi bila PPT predstavitev, telefonskih številk ni bilo napisanih; kje se dobi to na internetni strani, ni bilo napisano. Meni so dali tak vtis, kot da ne znajo uporabljat interneta. (Genex34)

Med prednostmi frankofonega univerzitetnega sistema navajajo bolj zložen ritem študijskega procesa, ki omogoča več refleksije in nudi priložnost, da v resnici pokažejo svoje znanje. Cenijo predvsem večjo ciljno usmerjenost. Ena od študentk je povedala, da je šele na izmenjavi začela resnično načrtovati svojo poklicno pot, ker je videla povezavo med predmetnikom in poklicnimi kompetencami.

Dejansko veš, kaj boš počel v prihodnosti, vsaj jaz osebno, sem se malo bolj zjasnila s cilji, ker tudi doma se mi velikokrat zdi, kot da nekaj plavaš, ne veš točno, zakaj si se to naučil, kaj ti bo pomagalo. Tam se mi pa zdi, (...) da imajo res fino razdeljene predmete, da se dopolnjujejo. Recimo tudi kritične predmete imajo, da jih naučijo razmišljat s svojo glavo (...). (Genex45)

Vključevanje v pedagoški proces od njih zahteva razumevanje organizacije študijskih aktivnosti. Presenečeni ugotovijo, da večina predavanj poteka $v$ velikih predavalnicah, vaj, ki so jih bili vajeni na slovenski fakulteti, pa tam nimajo. Seznanijo se z novo terminologijo in s koncepti, ki jih v domačem okolju niso poznali. Ena od študentk pove, da je bila presenečena, ko je opazila, da izraz dissertation označuje tisto, kar je v domačem okolju poznala kot esejski izdelek. Šele izkustveno spoznavajo vsebino teh konceptov in ugotavljajo, kakšne posledice imajo za njihov študij:

Imel si pa tudi (...) cours d'ouverture, to je bilo pa ful dobro, to so bila pa gostujoča predavanja, preko katerih si tudi lahko dobil kredite, ponavadi dva kredita. Si imel pa gostujočega profesorja, si imel dva tedna malo bolj intenzivno pri tem profesorju, na koncu si imel nek izpit, pripravil nek izdelek in če si opravil, si dobil 2 KT. (Genex46)

Pri organizaciji predavanj jih zanima, kakšne so zahteve za njihovo vključevanje v študijski proces. Večinoma so zadovoljni, da v nasprotju z domačo institucijo, kjer so morali 
literaturo prebrati pred predavanjem na določeno temo, v novem okolju niso prisiljeni $\mathrm{v}$ sprovocirane debate o literaturi, ki je niso prebrali. Opazijo, da vizualne predstavitve, ki so na domači instituciji vsakdanja praksa, v frankofonem okolju pogosto ne spremljajo predavanj. Zato težje sledijo strukturi in težje vzpostavljajo hierarhične odnose med posameznimi deli predavanj. Iz domačega okolja niso vajeni pisanja zapiskov. Nasprotno pa v frankofonem okolju opazijo, da večina študentov vestno beleži vsebino predavanj, zato so si zapiske izposojali od rojenih govorcev:

S Francozi smo se dogovarjali, ker pri njih je pa tako, da zapišejo vsako besedo, ki jo profesor pove. Tako da smo potem res imeli v redu zapiske. (GenexpSpS53)

Poseben izziv jim predstavljajo veščine znanstvenega pisanja, ki so jih v domačem okolju že usvojili. Čeprav sicer večinoma pričakujejo, da bodo morali svoje izdelke prilagoditi zahtevam gostujoče institucije, ne vedo natančno, kaj bodo te zahteve vključevale. V nasprotju z domačo institucijo, kjer od njih zahtevajo kratke izdelke, jih zmede že to, da morajo pripravljati precej daljše izdelke, za katere se spričo jezikovnih težav ne čutijo sposobni. Na nekaterih programih ugotavljajo, da je kriterij za ustreznost izdelka predvsem vsebina; na drugih, zlasti pri študentih, ki se vpišejo v program Certificat d'Etudes Politiques, v okviru posebnih metodoloških predavanj pobliže spoznajo francoski način argumentacije in tvorbe besedil. Proces učenja akademskega pisanja se jim zdi naporen, ne razumejo natančno, zakaj se morajo tvorbe besedil lotiti na nov način, vedo pa, da gre za veščino, ki se je francoski rojeni govorci učijo že od otroštva. Zdi se jim, da so zaradi oblikovnih zahtev prisiljeni v iskanje argumentov, ki jih nikakor ne morejo razvrstiti na predpisani način.

Tisto je bila katastrofa, ker je bila takšna razlika v tem, kako tukaj razmišljamo, da sem na začetku, preden sem se zverziral, porabil izjemno veliko časa, preden sem sploh uredil strukturo, in potem je bilo veliko manj časa tudi za razmišljanje o vsebini. (genEpS52)

Eden od študentov opaža, da se je pri pripravi esejev in drugih pisnih izdelkov od njih pričakovalo, da bodo v družboslovne tematike vnašali tudi filozofijo, kar naj bi bil izključno francoski pristop, in je posledično za mnoge tuje študente to predstavljalo nepremostljivo oviro. Večini en semester ne zadošča za funkcionalno rabo teh spretnosti. Nekateri pa kljub temu ugotovijo, da jih novi način razmišljanja spodbudi k globljemu razumevanju. Zlasti cenijo, da pri profesorjih na pozitiven odziv naleti kritično razmišljanje, česar v domačem okolju niso bili vajeni:

In na koncu je bilo pa treba povedat svoje mnenje, kar mi je bilo čisto novo. To je bilo natančno opredeljeno. Na FDV tega ne delamo, pri njih je pa to zelo zaželeno, tudi če kritično razmišljaš o vsem. (Genex33) 
Tudi priprave na izpite in ocenjevanje sta preizkušnji, ki jih destabilizirata, ne samo zaradi napornejšega učenja $v$ drugem tujem jeziku, ampak tudi zato, ker so v domačem okolju vajeni zelo visokih ocen, ocene pridobljene na izmenjavi, pa si težko interpretirajo. Ena od študentk pove, da najprej ni razumela, kaj pomeni ocena $13 \mathrm{v}$ njenem potrdilu, nato pa je vprašala francoske kolege, ki so ji razložili, da gre za odlično oceno in da je lahko ponosna nanjo.

Pri naših intervjuvancih lahko zaznamo, da je kljub načelni identitetni inkluzivnosti njihovo razumevanje akademske kulture zaznamovano $\mathrm{z}$ veliko negotovostjo, ker morajo ob prihodu $\mathrm{v}$ frankofono okolje pretrgati pridobljene stare rutine. $\mathrm{V}$ celotnem študijskem procesu zato opažajo predvsem razlike med kulturama, saj imajo občutek, da jim doma pridobljeno znanje in spretnosti pogosto ne koristijo pri vključevanju v akademsko skupnost, ampak jih celo ovirajo.

\subsection{Ovire pri uspešni medkulturni komunikaciji}

Iz pripovedi študentov je razvidno, da se zavedajo razlik med akademsko kulturo domače in gostujoče institucije, a jih v medkulturnih stikih pogosto težko premoščajo. Med omejitvenimi okoliščinami pri vzpostavitvi stabilnih, vzajemnih in funkcionalnih odnosov v frankofonem okolju omenjajo dejavnike čustvene, kognitivne in materialne narave.

Večina naših intervjuvancev pove, da so imeli na začetku manjšo krizo. V skupini čustvenih zaviralcev medkulturno usmerjenega delovanja je najbolj izstopajoč strah. Nekateri niti ne morejo opredeliti razloga za to čustvo, ampak trdijo, da jih je bilo strah čisto vsega. Drugi se primarno bojijo, da pri študiju ne bodo uspešni zaradi slabo razvitih jezikovnih zmožnosti ali zato, ker bi za funkcionalno akulturacijo potrebovali več časa ali pa zato, ker zahtev novega okolja niti ne morejo osmisliti. Pri tem izstopajo štirje glavni razlogi za stres: negotovost zaradi organizacijskih vidikov bivanja, nerazumevanje univerzitetnega sistema, jezikovni primanjkljaj in izključenost.

V kategorijo organizacijskih vidikov bi lahko uvrstili splošno dojemanje okolja kot kaotičnega. Študenti organizacijo na fakulteti opisujejo kot pomanjkljivo. Počutijo se ogrožene, ker zahtevne administrativne postopke in stike $\mathrm{z}$ administracijo ter urejanje bivanja doživljajo kot zelo stresne in dolgotrajne, medtem pa nimajo dostopa do nadomestila, ki jim kot študentom na izmenjavi pripada:

Ampak, če jim ne dostaviš papirjev na roko, potem se postopek tako zavleče, da ti denarja ne dobiš. Jaz sem še v tem postopku, tako da ne vem... Še vedno. In sem dala prošnjo, mislim da novembra. Smo pa julija. (Genex34)

Nekateri imajo celo težave z namestitvijo. Eden od študentov nam pove, da je bilo njegovo bivanje na začetku zelo »divje«, ker je ob prihodu na fakulteto izvedel, da zaradi 
velikega števila prošenj zanj ni mesta v študentskem domu, tako da je, dokler ni našel stanovanja, prenočeval pri kolegu z druge fakultete.

Negotovost in strah pred akademskim neuspehom izhajata iz kognitivne zahtevnosti študijskih vsebin, dvomov o jezikovnih zmožnostih in iz psihične obremenitve, ki jo čutijo spričo obilice študijskih zahtev v danih časovnih omejitvah. Nekateri ne vedo, ali prav razumejo, kaj se od njih sploh zahteva. Predavanjem na začetku sledijo le s težavo. Strah pred obvladovanjem kompleksnih študijskih vsebin še posebej občutijo podiplomski študenti, ki so ob prehodu na magistrski študij zamenjali študijsko področje, bodisi, da so prešli na novo področje ali na bolj specializirano mednarodno področje.

Vendar pa je zanimivo, da pri večini strah pred akademskim neuspehom ne izvira iz strokovno prezahtevnih vsebin, temveč iz najrazličnejših jezikovnih primanjkljajev. Pri vseh intervjuvancih so slednji med najpogosteje spontano in eksplicitno omenjenimi razlogi za omejen uspeh pri akulturaciji, saj jih spremljajo vse od pisanja motivacijskega pisma ter intervjuja do opravljanja izpitnih obveznosti. Večina jih poroča, da so ob prihodu v Francijo opravili uvrstitveni test, na katerem so pokazali zadostno raven jezikovnih zmožnosti. Kljub temu opažajo, da so njihove zmožnosti slušnega razumevanja prešibke, da bi lahko sledili predavanjem in hkrati delali zapiske. Zaradi hitrega tempa in omejenega besednega zaklada težko sledijo govorcu in se počutijo izgubljeni. Zapiski so večinoma pomanjkljivi in neuporabni pri študiju. Branje strokovne in znanstvene literature jim predstavlja izziv celo, kadar dobro poznajo tematiko. Ena od študentk nam zaupa:

$V$ začetku vem, da ko sem brala, se mi je zdelo, kot da berem v kitajščini. (GenexpSpS53)

Najbolj stresna pa se jim zdita tvorba pisnih sporočil in ustna komunikacija. Kot je nakazala že študija Diamantijeve (2011) pri italijanskih študentih v frankofonem okolju, tudi slovenski študentje čutijo primanjkljaj v obvladovanju tehnik argumentacije. Razvijanju te spretnosti so posvetili največ časa v organiziranih oblikah študijskega procesa, zaposlovale pa so jih tudi pri samostojnem pisanju izdelkov in pri opravljanju pisnih izpitov. Pri tvorbi pisnih sporočil jim poleg nepoznavanja pravil akademskega pisanja oviro predstavljajo ohlapna pravila za pripravo izdelkov in posledično nerazumevanje zahtev. Z jezikovnega vidika opažajo, da imajo težave $\mathrm{z}$ aktivno rabo neutrjenega besedišča in struktur ter $\mathrm{s}$ prilagajanjem slogovnim zahtevam. Pri ustni komunikaciji se ne čutijo dovolj kompetentni, ker menijo, da morajo razviti aktivno rabo besedišča tako v vsakdanji komunikaciji kot pri sodelovanju v študijskem procesu. V vsakdanji komunikaciji se namreč srečujejo tudi z neknjižnimi izrazi, pri strokovni komunikaciji pa omenjajo, da jih ovirata nepoznavanje terminologije ter nezmožnost hitrega reagiranja v študijski situaciji. Ena od študentk npr. pove, da ni mogla ustrezno sodelovati v simulacijah pogajanj, saj si je morala svoje sporočilo najprej zabeležiti, nato ga je bila šele pripravljena izreči.

Lahko bi torej sklenili, da se naši intervjuvanci v frankofoni skupnosti zaradi ovir pri funkcionalni komunikaciji soočajo s težavami pri rabi vseh jezikovnih zmožnosti. 
V zadnjo skupino dejavnikov stresa smo uvrstili okoliščine, ki izzovejo občutke ločenosti in marginalizacije. To je v manjši meri čutiti pri podiplomskih mednarodnih študentih kot pri študentih na izmenjavi. Ti opažajo, da večina interakcij poteka v okviru skupnosti Erasmus, čemur je prilagojen celoten sistem. Študenti, ki niso nastanjeni v študentskem naselju, se poleg tega počutijo izolirane, ker živijo v soseskah, kjer ne morejo komunicirati z rojenimi frankofonimi govorci:

Živela sem skoraj v enem getu, kjer so bila socialna stanovanja. Večinoma so bile tam družine iz Maroka oz. Severne Afrike. In jaz sem pač blond (smeh). Tako da je bilo občasno zelo nerodno hodit po tej soseski. Tudi Francozov tam ni-čisto fizično so na drugi strani mesta. Jaz pa sem bila sama tam sredi. (Genex33)

Pri opravljanju študijskih obveznosti za njih veljajo posebni študijski režimi in večinoma ugotavljajo, da njihovi izpiti niso enaki izpitom francoskih študentov. Govorilnih ur, ki so jih vajeni v slovenskem sistemu, ni, tako da se o svojih dosežkih ne morejo pogovoriti s profesorji. Tudi zahteve po upoštevanju novih pravil znanstvenega pisanja nekateri doživijo kot vzpostavljanje distance med domačimi in tujimi študenti in kot prioriteto forme nad vsebino:

In dobesedno, tako kot sem vam prej rekla, so nam povedali v prvem tednu. Zdaj morate pozabit vse, kar ste se prej naučili in se boste morali pač to leto prilagoditi nam. Kar je verjetno edino v Franciji sprejemljivo, da to rečejo. In potem smo imeli skoraj eno tretjino leta trening, kako pisat te eseje. (genEexpS56)

Kljub temu, da si rojeni govorci prizadevajo vključevati študente na izmenjavi v dejavnosti na fakulteti, opažajo, da osebje pogosto ni pripravljeno na komunikacijo z izmenjavnimi študenti, kar slednji prepoznajo kot aroganten odnos.

\subsection{Strategije razreševanja težav medkulturne narave}

Da bi se uspešno vključili v novo akademsko skupnost, naši intervujvanci uporabljajo mešanico strategij. Svoje jezikovne primanjkljaje si prizadevajo v kar največji meri odpraviti z udeležbo na jezikovnih izpopolnjevanjih, z obnavljanjem in utrjevanjem pridobljenega jezikovnega znanja, s samostojnim učenjem in vnaprejšnjo pripravo na predavanja. Tisti, ki so sprejeti na program CEP, so deležni širšega vpogleda v metodološke in kulturne vidike delovanja frankofone univerzitetne ter širše skupnosti. Vendar pa je videti, da cilj vzajemnosti jezikovnih izmenjav pri večini kljub temu ostaja nedosežen ideal.

Skupnost Erasmus deluje kot naravno zatočišče za študente na izmenjavi. Znotraj te skupnosti se počutijo varne in povezane v tujem okolju, ker opazijo, da se tudi ostali soočajo 
s podobnimi težavami. Zato mnogi iščejo podporo v tej skupnosti. Zdi pa se, da je stopnja integracije v frankofono skupnost odvisna tudi od tega, koliko se študent uspe odlepiti od skupnosti Erasmus. Pri opravljanju študijskih obveznosti zato nekateri študenti iščejo pomoč pri rojenih govorcih, zlasti pri študentih, v manjši meri pa tudi pri profesorjih. Eden od študentov slikovito opiše, kako je uspel izstopiti iz skupnosti Erasmus:

Splaval sem pa tako, da sem se začel družit s francoskimi študenti, s francosko govorečimi študenti, ki ne znajo prav dobro govorit francosko, začel koketirat s francoskimi puncami in šel na zmenek s francosko punco, ki ni imela pojma o angleščini in potem sem se tam moral znajt. In to so zelo zanimive situacije, ko probaš nekaj dopovedat. Ja na tak način...(Genex46)

S tem ne izboljšujejo samo svojih jezikovnih zmožnosti, ampak jim uspe opraviti z nekaterimi stereotipi, ki so jih imeli ob prihodu v frankofono okolje. Ena od študentk je bila npr. presenečena, ko je ugotovila, da so francoski profesorji zavzeli kritično držo do lastnega političnega sistema, saj je bila pred izmenjavo prepričana, da so Francozi tako ponosni na svojo državo, da česa takega ne bi bili sposobni narediti.

Čeprav se že na začetku zavedajo, da se bodo morali v novem okolju prilagajati in popuščati, postopoma ugotovijo, da pri tem ne gre za proces, v katerem izgubljajo, ampak je to zanje pozitivna izkušnja, kar ena od intervjuvank označi kot iskanje »sredine med dvema pogledoma«. Pri tem so odnosi vzajemni. Študenti namreč opazijo, da se jim prilagajajo tudi profesorji in ostalo osebje na frankofoni instituciji. Zdi se jim, da profesorji razumejo njihove težave, nerojenim govorcem prilagajajo študijske cilje in način dela: študenti pri njih zaznajo odprtost ter popustljivost v primerjavi z rednimi študenti.

Analizo strategij reševanja medkulturnih vprašanj lahko sklenemo z ugotovitvijo, da se naši intervjuvanci ne zadovoljijo z marginaliziranim položajem, ampak v želji po vzpostavljanju vzajemnosti v odnosih na čim večjem številu področij praviloma razvijejo različne strategije za funkcionalno delovanje na čim večjem številu področij. Zato svojih težav medkulturne narave ne dojemajo kot negativne izkušnje, ampak kot proces rasti. Učinek tega procesa je večja neodvisnost, boljša prilagodljivost udeležencev v akademskem okolju ter želja po bolj poglobljenem spoznavanju nove kulture.

\section{SKLEP}

Namen pričujoče študije je bil osvetliti procese gradnje medkulturnih kompetenc pri večjezičnih učencih. Na temelju intervjujev smo dobili izčrpne podatke o načinu akulturacije slovenskega študenta nefilološke fakultete v frankofono univerzitetno okolje. Pri tem smo izpostavili elemente, ki v frankofonem okolju prispevajo $\mathrm{k}$ identitetni trdnosti in varnosti, ter elemente, ki na vzpostavljanje identitete delujejo omejitveno. Izsledki raziskave nas vodijo 
v širše teoretske razmisleke o poučevanju / učenju medkulturnih kompetenc pri tujem jeziku stroke, po drugi strani pa odgovarjajo tudi na konkretne potrebe študentske populacije.

Prvi teoretski razmislek se nanaša na vprašanje deležnikov pri učenju / poučevanju jezika za mednarodne študente v frankofonem okolju. Izkušnja naših študentov kaže, da njihova jezikovna priprava $v$ domačem okolju in prizadevanja za izboljšanje jezikovnega znanja v frankofonem okolju niso povezana. Da bi povečali predvidljivost rezultatov in zmanjšali čustveno komponento ter negativni stres pri tem procesu, bi bilo pri načrtovanju jezikovnih programov v omenjeno sodelovanje nujno vpeljati še enega akterja: učitelja na domači ustanovi izmenjavnega študenta. Drugo teoretsko vprašanje se odpira v povezavi s pogosto omenjenim vprašanjem prenosa izsledkov medkulturnih raziskav v poučevanje. Za potrebe didaktizacije in vrednotenja tujega jezika stroke namreč po našem védenju ne obstajajo kazalniki, ki bi omogočali bolj sistematično umeščanje medkulturnih parametrov v poučevanje. Nadalje je raziskava odprla vprašanje poučevanja medkulturnih kompetenc pri raznojezičnih govorcih. Analiza je pokazala, da je vključevanje medkulturnih vsebin pri poučevanju drugega tujega jezika veliko bolj pomembno kot pri poučevanju angleškega jezika za študijske namene.

Glede na to, da gre pri študentski populaciji, ki smo jo proučevali, za integrativno usmerjene osebnosti, bi bilo treba preveriti, v kolikšni meri in na kakšen način se medkulturne kompetence iz prvega tujega jezika lahko prenesejo v poučevanje drugega tujega jezika in katere specifične kompetence je treba razvijati v okviru francoščine kot drugega ali tretjega tujega jezika. Nenazadnje bi bilo glede na raznolikost jezikovnih izkušenj študentov koristno pripraviti model za vključevanje tovrstnih vsebin v programe jezika stroke.

Na temelju izsledkov pa lahko podamo tudi nekaj praktičnih predlogov. Naši intervjuvanci so pokazali zelo izostren čut za dojemanje razlik med kulturama, kar že samo po sebi v fazi stresa povečuje njihovo ranljivost, v fazi gradnje medkulturnih kompetenc pa prispeva k večji stabilnosti. Njihova identiteta $v$ frankofonem okolju je v načrtnem preoblikovanju, izkaže se kot večplastna, fluidna in navzven odprta. Sama ugotovitev glede na družboslovno usmerjenost študentov ni presenetljiva, vsekakor pa pomeni pomembno prednost, ki bi jo veljalo izkoristiti pri uvajanju medkulturnih vsebin, ne samo z vidika informativne vrednosti posredovanih podatkov, ampak tudi z vidika analitičnih kompetenc študentov v vlogi učencev tujega jezika. Hkrati njihova opažanja kažejo na kompleksnost potreb pri študiju v frankofonem okolju. Te daleč presegajo tradicionalno ozko usmerjenost programa $\mathrm{v}$ jezik stroke in ponovno poudarjajo pomen posredovanja znanja o ciljni kulturi v najširšem pomenu besede.

Kar zadeva razvoj jezikovnih zmožnosti, so študenti posebej poudarili potrebo po sistematični gradnji besedišča, izboljševanju slušnega razumevanja s poslušanjem predavanj in pripravi zapiskov predavanj. Kot največjo težavo so izpostavili tvorbo uradovalnih in akademskih besedil. Vsi ti elementi ustrezajo parametrom, ki so jih prepoznale že predhodne mednarodne in frankofone študije (npr. Monballin in dr. 1995, Camiciottoli 2010, Mangiante 2012) in jih v svojem priročniku za poučevanje jezika za študijske namene vključujeta 
tudi Mangiante in Parpette (2011), vendar bi jim bilo treba na temelju izkušenj slovenskih študentov dodati še vsaj tri ugotovitve.

Prvič, priprava na izmenjavo v frankofonem okolju je celo za študente, ki imajo na svoji domači instituciji možnost izbrati francoščino kot tuji strokovni jezik, dolgotrajen postopek, ki zahteva seznanjanje tako s področjem študija kot s ciljno akademsko kulturo že pred odhodom na izmenjavo. Brez tovrstne predpriprave $\mathrm{v}$ frankofonem okolju se študenti sicer začnejo zavedati medkulturnih razlik, vendar jih včasih niso sposobni interpretirati in o njih nimajo sistematičnega znanja.

Drugič, naši intervjuvanci akademsko skupnost dojemajo kot izziv za svojo identitetno varnost. Ogrožajo jo zlasti nepoznavanje mehanizmov akademskega pisanja, pomanjkljive tehnike vzpostavljanja vzajemnosti odnosov ter občutek akademske in fizične marginalizacije. Priložnosti za soočanje s takimi izkušnjami bi morali imeti študenti pred odhodom na izmenjavo v frankofono okolje. Posebno pozornost bi bilo treba posvetiti analizi potreb študentov, ki vse svoje obveznosti v frankofonem okolju opravljajo v angleščini in se s težavami v medkulturni komunikaciji srečujejo na drugačen način kot francosko govoreči študenti.

Tretjič, učitelji bi morali tudi pri poučevanju jezika stroke tovrstne vsebine sistematično vključevati v programe, bodisi v obliki posebnega modula ali pa v kaki drugi obliki, ki bi ustrezala njihovemu pristopu: npr. integrirana obravnava medkulturnih vidikov na način, da bi študentom ponudili izkustveno učenje opredeljenih vsebin v avtohtonih kontekstih. Kot so pokazale že predhodne raziskave v anglofonem okolju, za to obstajajo tudi številne možnosti s pomočjo informacijskih in komunikacijskih tehnologij. Podrobnejša diskurzivna analiza različnih tipov besedil v maternem in francoskem jeziku v protistavni perspektivi in analiza procesov dojemanja ter usvajanja teh razlik bi omogočila bolj ciljno usmerjeno delo na medkulturnih vsebinah.

Hkrati pa ima analiza intervjujev z izbranega vidika za posploševanje izsledkov določene omejitve. Prva omejitev je povezana z velikostjo populacije. Število intervjuvanih študentov je bilo sorazmerno majhno, vendar pa je v primerjavi z izmenjavami, ki pretežno potekajo v angleškem jeziku, majhna tudi celotna populacija slovenskih študentov nefiloloških fakultet, ki del svojih študijskih dejavnosti opravijo v frankofonem okolju. Drugo omejitev postavlja kompleksnost konceptov identitete in akulturacije. Študije identitete in akulturacije so namreč pokazale, da poleg medkulturne ozaveščenosti na način in uspeh gradnje identitete ter na percepcijo medkulturnih vprašanj v univerzitetnem okolju vplivajo tudi številni drugi dejavniki, kot so npr. dosežena jezikovna raven, doseženi študijski rezultati in način gradnje identitete v okolju,domače ' institucije (Smith in Khawaja 2011), česar pa nismo raziskovali $v$ tej analizi.

Upamo, da so izsledki naše raziskave pripomogli k razumevanju kompleksnosti medkulturne kompetence in s tem nakazali možne vzvode, ki vodijo k premagovanju ujetosti v polarizirano dojemanje kulturnih vzorcev izhodiščne in frankofone kulture ter h gradnji medkulturno ozaveščenih osebnosti. 


\section{VIRI}

BRISSET, Camille/Saba SAFDAR/J. REES LEWIS/Colette SABATIER (2010) Psychological and sociocultural adaptation of university students in France: The case of Vietnamese international students. International journal of intercultural relations 34(4), 413-426.

CAMICIOTTOLI, Belinda Crawford (2010) Meeting the challenges of European student mobility: Preparing Italian Erasmus students for business lectures in English. English for Specific Purposes 29(4), 268-280.

CANAGARAJAH, Suresh (2007) Lingua franca English, multilingual communities, and language acquisition. The Modern Language Journal 91(1), 923-939.

CARRAS, Catherine/Jacqueline TOLAS/Patricia KOHLER-BALLY/Elisabeth SZILAGYI (2007) Le français sur objectifs spécifiques et la classe de langue, CLE international.

CHALLE, Odile (2002) Enseigner le français de spécialité. Economica.

CHRISTIE, Frances/James Robert MARTIN (ed.) (2000) Genre and institutions: Social processes in the workplace and school. London/New York: Continuum.

CISLARU, Georgeta/Chantal CLAUDEL/Monica VLAD (2009) L'écrit universitaire en pratique. De Boeck.

COLEMAN, James A. (2006) English-medium teaching in European higher education. Language teaching, 39(01), 1-14.

DE CARLO, Maddalena (2013) Réflexions sur une compétence difficile à cerner: le savoirêtre. Ela. Études de linguistique appliquée 1, 93-107.

DERVIN, Fred (2010) Assessing intercultural competence in Language Learning and Teaching: a critical review of current efforts. New approaches to assessment in higher education, $155-172$.

DIAMANTI, Laura (2011) Pratiques didactiques et culture partagée: apprendre à s' intégrer dans un système universitaire autre en tant qu'étudiant Erasmus. Ela. Études de linguistique appliquée 162(2), 207-220.

DOYLE, Stephanie/Philip GENDALL/Luanna H. MEYER/Janet HOEK/Carolyn TAIT/ Lynanne MCKENZIE/Vatar LOORPARG (2010) An investigation of factors associated with student participation in study abroad. Journal of Studies in International Education 14(5), 471-490.

FLOWERDEW, John/Simon Ho WANG (2015) Identity in Academic Discourse. Annual Review of Applied Linguistics 35, 81-99.

HENRY, Alastair (2011) Examining the impact of L2 English on L3 selves: A case study. International Journal of Multilingualism 8(3), 235-255.

JAŠKOVÁ, Mária/Lenka HECZKOVÁ (2010) ERASMUS mobility: students motivation and satisfaction. In Erasmus coordinators conference.

KALIN GOLOB, Monika/Marko STABEJ/Mojca STRITAR KUČUK/Gaja ČERV/Samo KROPIVNIK (2014) Jezikovna politika in jeziki visokega šolstva v Sloveniji. Ljubljana: Založba FDV. 
KIM, Young Yun (2012) Beyond categories: Communication, adaptation, and Transformation. Handbook of language and intercultural communication. J. Jackson (ed.) New York: Routledge, 229-243.

KIM, Young Yun (2015) Finding a "home" beyond culture: The emergence of intercultural personhood in the globalizing world. International Journal of Intercultural Relations 46, 3-12.

KIM, Young Yun (2009) The identity factor in intercultural competence. The Sage handbook of intercultural competence. D.K. Deardorf, (ed.) Los Angeles, London, New Delhi, Singapore, Washington: Sage, 53-65.

LAH, Meta (2012) Medkulturno skozi čas: medkulturne vsebine v učbenikih francoščine kot tujega jezika. Ars \& humanitas 6(2), 103-116. 29. september 2015. http://revije. ff.uni-lj.si/arshumanitas/article/view/376/288.

LAH, Meta in ostali (2008) Učni načrt. Francoščina: Gimnazija; Splošna, klasična, strokovna gimnazija. Obvezni ali izbirni predmet (420 ur), matura (predvidene dodatne ure). Ljubljana: Ministrstvo za šolstvo in šport: Zavod RS za šolstvo.

MANGIANTE, Jean-Marc/Chantal PARPETTE (2004) Le Français sur Objectif Spécifique: de l'analyse des besoins à l'élaboration d'un cours, Paris: Hachette.

MANGIANTE, Jean-Marc/Chantal PARPETTE (2011) Le français sur objectif universitaire, Grenoble: Presses universitaires de Grenoble.

MANGIANTE, Jean Marc (2012) Le Français sur Objectif Universitaire: de la maitrise linguistique aux compétences universitaires. Synergies Algérie 15, 147-166.

MONBALLIN, Michèle/Myriam van der BREMPT/Georges LEGROS (1995) Maîtriser le français écrit à l'université: un simple problème de langue? Revue des sciences de l'éducation 21(1), 59-74.

PAPATSIBA, Vassiliki (2006) Study abroad and experiences of cultural distance and proximity: French Erasmus students. Languages for Intercultural Communication and Education 12, 108-133.

PAQUIN, Maryse/Sabine-Claudia HOCK (2014) Les rencontres interculturelles entre étudiants universitaires dans le cadre d'un séjour d'études à l'étranger. Alterstice-Revue Internationale de la Recherche Interculturelle 4(1), 3-16.

PITTS, M. J. (2009) Identity and the role of expectations, stress, and talk in short-term student sojourner adjustment: An application of the integrative theory of communication and cross-cultural adaptation. International Journal of Intercultural Relations 33(6), 450-462.

SEIDMAN, Irving (2006) Interviewing as Qualitative Research: A Guide for Researchers in Education and the Social Sciences. New York in London: Teachers College Press.

SMITH, Rachel A./Nigar G. KHAWAJA (2011). A review of the acculturation experiences of international students. International Journal of Intercultural Relations 35(6), 699-713.

SWALES, John (1997) English as Tyrannosaurus Rex. World Englishes, 16(3), 373-382. 
TEICHLER, Ulrich (2004) The changing debate on internationalisation of higher education. Higher education 48(1), 5-26.

TEICHLER, Ulrich (2009) Internationalisation of higher education: European experiences. Asia Pacific Education Review 10(1), 93-106.

VENTOLA, Eija/Anna MAURANEN (eds.) (1996) Academic writing: Intercultural and textual issues. Vol. 41. John Benjamins Publishing.

WALFORD, Geoffrey (ed.) (2001) Doing qualitative educational research. London: Continuum.

\section{POVZETEK}

»Zdaj morate pozabit vse, kar ste se prej naučili«: gradnja medkulturnih kompetenc pri slovenskih študentih nefilološke fakultete $v$ frankofonem akademskem okolju

Internacionalizacija visokega šolstva je v zadnjih desetletjih postala splošno priznano dejstvo in nujnost evropskega prostora. Med pomembnimi posledicami internacionalizacije sta tudi povečana mobilnost študentov in uporaba angleščine kot lingue france $\mathrm{v}$ pedagoškem procesu na univerzitetni ravni. Vendar pa študenti vseh aktivnosti na gostujoči instituciji ne morejo ali ne želijo vedno opraviti v angleškem jeziku, zato je za njihovo uspešno mednarodno izkušnjo pomembno tudi poznavanje drugega tujega jezika. Skozi perspektivo nezadostnih jezikovnih kompetenc v drugem tujem jeziku se pri tem odpirajo vprašanja študentovih predstav o tuji akademski kulturi in o načinu bivanja znotraj te kulture. Namen pričujoče raziskave je ugotoviti, s kakšnimi omejitvami, povezanimi z gradnjo medkulturnih kompetenc, se srečujejo slovenski študenti nefilološke fakultete ob opravljanju študijskih obveznosti na frankofoni instituciji. Na temelju polstrukturiranih intervjujev, ki smo jih opravili s študenti Fakultete za družbene vede, smo s kvalitativno tekstovno analizo ugotavljali, kako študenti na izmenjavi in študenti na podiplomskem študiju v frankofonem okolju konceptualizirajo svojo identiteto in kako dojemajo značilnosti frankofone kulture. Rezultati kažejo, da pri študentih prevladuje identitetna inkluzivnost, identitetno varnost pa poleg jezikovnih primanjkljajev ovirajo predvsem pomanjkljivo razumevanje akademske kulture in občutki marginalizacije v odnosu do študentov, ki jim je francoščina materni jezik. V zadnjem delu podajamo nekaj predlogov za razvijanje medkulturne kompetence učencev jezika stroke na nefilološki fakulteti.

Ključne besede: mednarodna mobilnost, francoščina kot jezik stroke, medkulturna kompetenca, identiteta, frankofona kultura

\section{ABSTRACT}

"You Should Forget What You Have Learned so Far«: Building Intercultural Competences in Slovene Students of a Non-Philological Faculty during Their Stay at a French-Speaking University

The internationalisation of higher education has become a generally acknowledged fact as well as a requirement in the European context. As a result, universities have been faced with increased student 
mobility and the use of English as a lingua franca. However, students may find themselves in situations in which they cannot or do not want to use English in completing their study obligations at their host institution. In this case, the knowledge of a different foreign language is required for a successful international experience. Issues of students' conception of a foreign academic culture and of being immersed in this culture arise through a perspective of language deficiencies in L3 (students' second foreign language). The aim of this study is to identify obstructions to the successful building of intercultural competences in the specifically francophone environment. Semi-structured interviews were carried out among a group of Slovene undergraduate and graduate social sciences students at a French host institution. Through qualitative text analysis, we examine how Slovene students conceptualise their identity and how they perceive various characteristics of the francophone academic environment. The results suggest that the interviewees' construction of intercultural competences is generally characterised by identity inclusivity, while identity security is obstructed by deficient language skills, incomprehension of academic culture, and feelings of marginalisation in relation to native speakers of the French language. Some pedagogical implications for the development of intercultural competence on the part of language learners at a non-philological faculty are discussed in the final section.

Key words: international mobility, French for specific purposes, intercultural competence, identity, francophone culture

\section{RÉSUMÉ}

\section{« Il faut oublier tout ce que vous avez appris »: construction de compétences interculturelles chez les étudiants de filières non-philologiques slovènes en mobilité dans les universités franco- phones}

Au cours des dernières décennies, l'internationalisation du milieu universitaire devient un fait incontestable et une nécessité dans le contexte européen. Cette nouvelle réalité engendre entre autres une mobilité étudiante accrue et l'usage de l'anglais en tant que lingua franca académique. Or les étudiants ne peuvent pas ou ne veulent pas toujours utiliser l'anglais pour compléter leurs études au sein d'une institution d'accueil. Les éventuelles insuffisances au niveau des compétences linguistiques en L3 (la deuxième langue étrangère) ouvrent un certain nombre de questions sur la perception de la culture universitaire à l'étranger et sur la manière d'être dans cette culture. L'objet de cette recherche est d'identifier les obstacles, liés à la construction des compétences interculturelles, que rencontrent les étudiants d'une faculté non philologique slovène lors de leur séjour au sein d'une institution académique francophone. Des entrevues semi-structurées ont été effectuées auprès des étudiants et des diplômés de la Faculté des Sciences Sociales de Ljubljana. Une analyse qualitative a été menée dans le but de comprendre comment les étudiants en mobilité perçoivent leur identité et les caractéristiques de la société francophone. Les résultats montrent que le groupe étudié est majoritairement caractérisé par l'inclusivité identitaire. La sécurité identitaire est entravée surtout par trois éléments : déficiences linguistiques, incompréhension de la culture académique et sentiments de marginalisation par rapport aux étudiants 'autochtones'. La dernière partie aborde les implications pédagogiques de ces résultats tout en proposant un développement et renforcement de la compétence interculturelle auprès des apprenants de français au sein d'une faculté non philologique.

Mots-clefs: mobilité internationale, français sur objectifs spécifiques, compétence interculturelle, identité, culture francophone 